\title{
Continuous positive aimay pressure in childhood obstructive sleep apnea syndrome
}

\author{
G. Aubertin
}

Pediatric pneumologist, Pediatric Pneumology Dept, Rare Childhood Respiratory Diseases Reference Center, Armand Trousseau Hospital, Paris, France

\section{SUMMARY}

Obstructive sleep apnea syndrome is probably the most frequent indication for continuous positive airway pressure in children. In some cases, non-invasive two-level ventilation is necessary. Many interfaces are commercially available for children, allowing personalized treatment: nasal or facial masks, or nasal prongs. There are no validated criteria, in terms of age or the disease, for initiating CPAP therapy in children. Close surveillance of facial growth is indispensable.

\section{KEY-WORDS}

Obstructive sleep apnea syndrome, children, treatment, CPAP

Nocturnal respiratory assistance using continuous positive airway pressure (CPAP) is one means of treating childhood obstructive sleep apnea syndrome (OSAS).

\section{CPAP: INDICATIONS AND EFFICACY}

In children as in adults, CPAP is part of the therapeutic armamentarium for OSAS without lymphoid tissue hypertrophy or OSAS persisting after adenotonsillectomy or orthodontic treatment. Efficacy derives from reduced upper airway resistance, by creating a pneumatic "splint" that increases airway caliber. CPAP has been shown to be effective in reducing OSAS symptoms ${ }^{4}$ and complications: nocturnal gas exchange anomalies, increased respiratory effort, impaired growth, metabolic syndrome and neurocognitive impact.

The "fixed" CPAP technique maintains constant airway opening throughout the respiratory cycle by delivering constant pressure. Automated CPAP $^{6}$ adapts the pressure within a preset range, targeting

Address for correspondence:

Guillaume Aubertin

26 Avenue du Docteur Arnold-Netter

75012 Paris, France

E-mail: guillaume.aubertin@trs.aphp.fr

Article received: January 8, 2015. Accepted for publication: February 25, 2015.

This is an Open Access article distributed under the terms of the Creative Commons Attribution License (http://creativecommons.org/licenses/by/4.0), which permits unrestricted use, distribution, and reproduction in any medium, provided the original work is properly cited. 
detected obstruction. However, manufacturers' specifications need to be checked to make sure the device used is able to detect residual apnea and hypopnea: some models are effective only in children weighing more than $30 \mathrm{~kg}$. The ventilator's internal logarithm also needs to be known, as the technique is derived from adult applications. Present-day ventilators detect only apnea exceeding $10 \mathrm{sec}$ and underestimate residual apnea in children: in adults, apnea is defined as $>10 \mathrm{sec}$ interruption of airflow, whereas in children it is an interruption of $>2$ cycles (thus, usually less than $10 \mathrm{sec}$ ). Automated CPAP is little used in children ${ }^{5}$.

There are no validated consensual criteria for implementing CPAP in childhood OSAS. Indications are founded on clinical examination and polygraphy or polysomnography. lit may also be tried in case of suggestive clinical symptomatology with only moderately pathological sleep examination. In contrast, CPAP should be initiated rapidly in case of nocturnal gas exchange anomaly.

Indications can be summarized as follows:

- before or after head and neck surgery;

- before, during or after orthodontic treatment;

- in case of failure of medical treatment;

- in OSAS without obstacle.

In OSAS, CPAP rapidly improves sleep quality and quality of life $^{4}$, but neurocognitive benefit is generally slow to manifest and is not always substantial ${ }^{3}$.

\section{IMPLEMENTING CPAP IN CHILDREN}

CPAP devices have single-branch circuits with intentional leakages to evacuate $\mathrm{CO}_{2}$. Outlets are generally integrated in the interfaces, but an expiration valve can also be fitted as close as possible to the interface if the latter has no built-in outlet. Numerous models are available, and the practitioner should be familiar with a certain number for children. To improve comfort and tolerance, a humidifier is used, generally built into to device.
The interface should be adapted to the child's face, comfortable, without unintended leakage. It usually consists of a mass-produced or custom-made nasal mask, the latter molded on the face itself7. Nostril plugs may also be used. Many interfaces, of all sizes, are now available; some can even be used in infants (fig. 1). The choice of mask is essential, as poor adaptation may be the sole cause of failure.

\section{STARTING AND MONITORING CPAP IN CHILDREN}

Other than in neuromuscular patholo$\mathrm{gy}^{9}$, there are no guidelines on initiating ventilation in children. CPAP is a medical prescription, best initiated within 


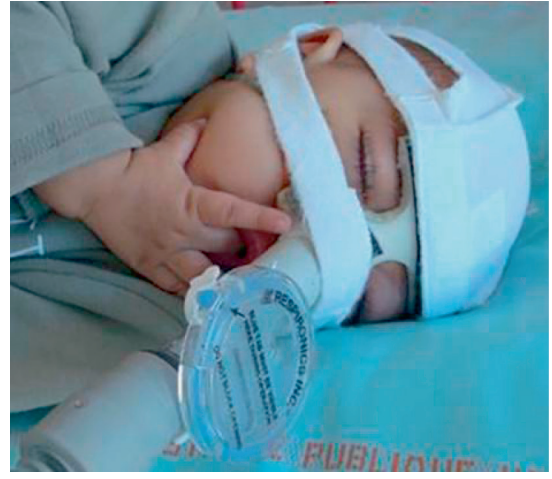

a

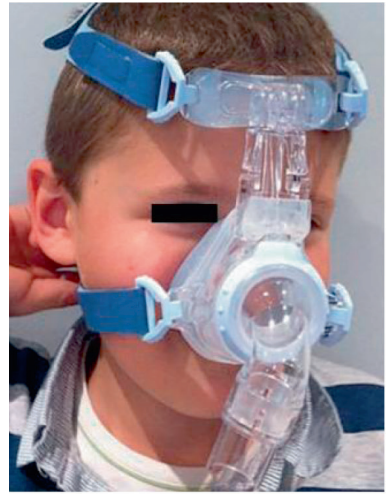

b
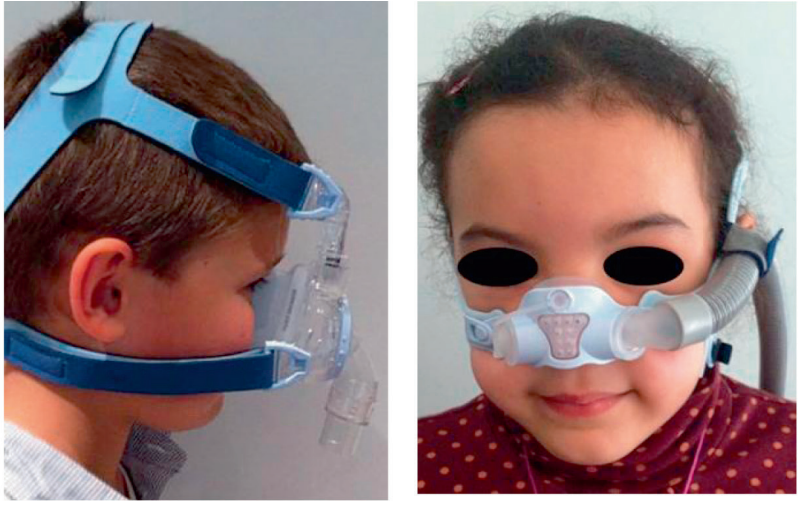

C

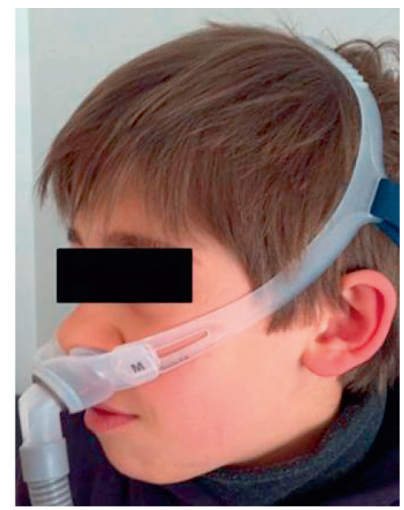

d

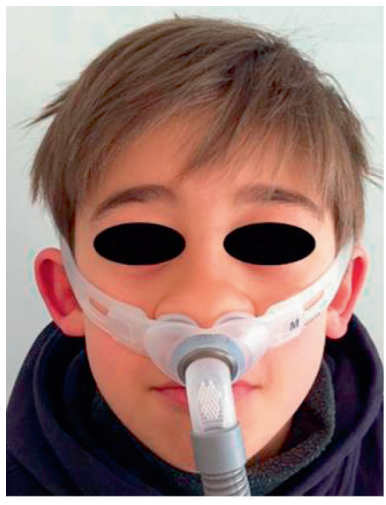

西

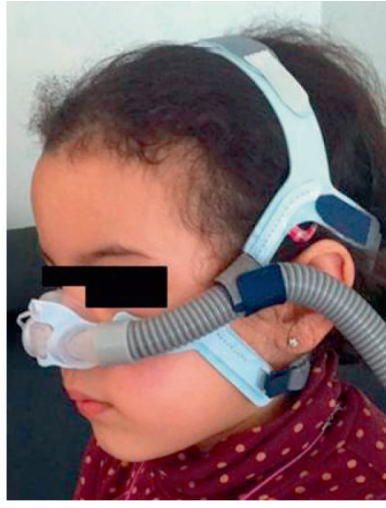

Figure 1

CPAP interfaces. (a) Custom-molded nasal mask with expiration valve. (b) Mass-produced nasal mask with outlets; frontal and lateral photographs. (c) Mass-produced nasal envelope, with outlets; frontal and lateral photographs. (d) Mass-produced nasal plugs, with outlets. 
an experienced multidisciplinary team, with a few days' hospital admission to allow adaptation. There is no "default setting" for the pressure parameters. The family has a vital role to play, and needs training. Therapeutic education of child and family is an essential factor for compliance8. At least 6 hours' continuous application is required. Initial monitoring is performed by the home service provider, with technical and paramedical staff trained in pediatrics, who will be the pivot between the family and the medical team. Longterm monitoring focuses on tolerance and efficacy, at a rhythm depending on the child's pathology and age, but is at least six-monthly. Interfacerelated side-effects may occur: skin intolerance, ranging from transient erythema to eschar or facial deformation (facial, flattening or retromaxillism). It is thus essential to monitor facial bone growth ${ }^{2}$. It may be necessary to change interfaces, to vary the pressure points. CPAP-related side-effects should also be screened for: unintended leakage (the most frequent cause of inefficacy), dry nose due to lack of humidification, digestive bloating, claustrophobia or insomnia. Device incidents and malfunction are rare?.

CPAP is usually implemented for a limited time in childhood OSAS without associated comorbidity, allowing continued facial bone growth (sometimes with the help of orthodontic treatment), but may sometimes be prolonged. Impact on facial bone growth should be checked regularly; the patient and family should be supported by the medical team and a service provider trained in pediatric practice, rapidly available in case of problems.

Conflicts of interest: The author has no conflicts of interest to disclose.

\section{REFERENCES}

1. Chatwin M, Heather S, Hanak A, Polkey MI, Simonds AK. Analysis of home support and ventilator malfu- nction in 1,211 ventilator-dependent patients. Eur Respir J 2010;35:310-6.

2. Fauroux $B$, et al. Facial side effects during noninvasive positive pressure ventilation in children. Intensive Care Med 2005; 31:965-9.

3. Gozal D, Pope DW Jr. Snoring during early childhood and academic performance at ages thirteen to fourteen years. Pediatrics 2001;107:1394-9.

4 Marcus $C L$, et al. Adherence to and effectiveness of positive airway pressure therapy in children with obstructive sleep apnea. Pediatrics 2006;117:e442-51.

5 Marcus $C L$, et al. Diagnosis and management of child- hood obstructive sleep apnea syndrome. Pediatrics 2012;130:e714-55.

6 Palombini L, Pelayo R, Guilleminault C. Efficacy of automated continuous positive airway pressure in children with sleep-related breathing disorders in an attended setting. Pediatrics 2004;113:e412-7.

7. Ramirez $A$, et al. Interfaces for long-term noninvasive positive pressure ventilation in children. Intensive Care Med 2012;38:655-62. 
8. Smith I, Nadig V, Lasserson TJ. Educational, support- ive and behavioural interventions to improve usage of continuous positive airway pressure machines for adults with obstructive sleep apnoea. Cochrane Database Syst Rev 2009;2:CD007736.

9. Modalités pratiques de la ventilation non invasive en pression positive, au long cours, à domicile, dans les maladies neuromusculaires. Recommandations AFM - HAS. May 2006. www.has-sante.fr. 